\title{
FORMULATION AND OPTIMIZATION OF NIFEDIPINE LOADED NANOCARRIERS
}

\author{
ASHWINI JADHAV*, BINOY VARGHESE CHERIYAN ${ }^{1}$
}

Department of Pharmaceutical Chemistry and Analysis, School of Pharmaceutical Sciences, Vels Institute of Science Technology and Advanced Studies (VISTAS) Tamilnadu, Chennai 600117, India

Email: ashwini.mali13@gmai.com

Received: 15 May 2021, Revised and Accepted: 29 Jun 2021

ABSTRACT

Objective: The main aim of this study to formulate a nifedipine-loaded nanocarrier for improving solubility and bioavailability.

Methods: To improve the solubility of drug, nifedipine-loaded nanocarrier (lipotomes) were prepared by using the film lipid hydration technique. lipotomes were prepared by using tween 80 , which is used for increasing solubility and cetyl alcohol for lipophilic environment. Drug excipients interaction determined by FTIR. lipotomes were characterized for particle size, Entrapment efficiency and zeta potential. lipotomes were optimized by using Design-Expert 12 software. Optimized formula further lyophilized by using different cyroproyectant to improve the stability and oral administration of the drug.

Results: FTIR shows there was no interaction between formulation ingredients. Mean particle size, entrapment efficiency, zeta potential was determined and found to be $308.1 \mathrm{~nm}, 96.7 \%, 20.1 \mathrm{mV}$, respectively. Surface morphology of lipotomes was observed by a scanning electron microscope (SEM). Optimized lipotomes was lyophilized with Mannitol $(8 \% \mathrm{w} / \mathrm{v})$ was the ideal cryoprotectant to retain the physicochemical characteristics of the OLT formulation after lyophilization.

Conclusion: Nifedipine loaded nanocarrier was successfully prepared, using film hydration method. Which have good particle size, EE\% and zeta potential. After lyophilization no significant changes was observed in particle size with good physical stability, so it could be a good choice for conventional drug delivery system by doing further investigation as in vitro and in vivo study

Keywords: Lipotomes, Solubility, Nifedipine, Lyophilization, Nanocarriers

(C) 2021 The Authors. Published by Innovare Academic Sciences Pvt Ltd. This is an open-access article under the CC BY license (https://creativecommons.org/licenses/by/4.0/)

DOI: https://dx.doi.org/10.22159/ijap.2021v13i5.42050. Journal homepage: https://innovareacademics.in/journals/index.php/ijap

\section{INTRODUCTION}

4-(2-Nitrophenyl)-2,6-dimethyl-3,5-dicarbomethoxy-1,4-dihydropyrid ine (Nifedipine) is under the class of calcium channel blocker,which is used for the treatment of angiocardiopathy. NI is poorly soluble in water $(20 \mu \mathrm{g} / \mathrm{ml})$. Although oral administration is the best convenient route and has better patient compliance; bioavailability of nifedipine has been limited by poor solubility, photo-instability, or short plasma half-life [1]. Improving solubility and membrane permeability could lead to enhance of oral bioavailability [2].

Many oral drugs like imipramine, morphine, lidocaine, etc. suffer from extensive first-pass effect, several methods were applied including changing the route of administration to rectal, injections, transdermal, intranasal, etc. to bypass the first-pass effect of the orally administered drugs [3-6]. Most preferred and favored route of administration by patients is oral route. To enhance the solubility of class II drugs in the GIT physiological conditions, several approaches have been developed including the formulation and development of nanocrystals, Micelles, Liposome's, Nanoparticles etc [7, 8].

Many limitations of different nanocarriers can be avoided through the selection of non-ionic surfactants with excellent biocompatibility profiles e. g. Tween $® 80$ and cetyl alcohol. Tween $® 80$ is safely used for oil-soluble vitamins as a solubilizer and its daily dose of administration is a 300 to $500 \mathrm{mg}$ [9]. Cetyl alcohol is used as a food additive and listed by the FDA as GRAS [10]. Tween $₫ 80$ is used as a surfactant to enhance the solubility of poorly water-soluble drugs and cetyl alcohol is utilized to impart a lipophilic environment and enhance lymphatic uptake [11]. Comparing to conventional liposomes, lipotomes are superior over the due to replacing the main liposomal components, i.e., phosphatidylcholine and cholesterol with Tween $\AA 80$ and cetyl alcohol. Due to ability to enzymatic degradation of liposome which contain Phosphatidylcholine shows low stability and high drug leakage in the GIT physiological conditions [12-14].

Drugs like budesonide, fluticasone propionate, chlorpromazine, verapamil, isradipine, felodipine, raloxifene, pentozocine base, dronedarone, lozartan and propafenone used as other candidates for lipotomes preparation [6]. Thin-film hydration technique. was used for the preparation of Lipotomes. Which is having an advantage over solid lipid nanoparticles which require more tedious and complicated methods of preparation [15].

\section{MATERIALS AND METHODS}

\section{Materials}

Nifedipine was gifted by Emcure pharmaceuticals,. Pune. Tween 80, Cetyl alcohol, (T80), mannitol, Aerosil, procured from Thermosil Fine Chem Pvt. Ltd. Pune.

All reagents were of the highest grade commercially available and other chemicals and solvents were of analytical grade and deionized distilled water was used for the preparation of all solutions.

\section{Construction of standard calibration curve for nifedipine}

Standard calibration curve of Nifedipine was developed using $0.1 \mathrm{~N}$ $\mathrm{HCl}$ and estimated by UV-Visible spectrophotometer at $239 \mathrm{~nm}$.

A stock solution of ( $1 \mathrm{mg} / \mathrm{ml})$ of standard drug was prepared; the 1 ml of stock solution was further diluted with $100 \mathrm{ml} 0.1 \mathrm{~N} \mathrm{HCl}$ to get $10 \mu \mathrm{g} / \mathrm{ml}$ (working standard). later required dilutions $(1 \mu \mathrm{g}, 2 \mu \mathrm{g}$, $3 \mu \mathrm{g}, 4 \mu \mathrm{g}, 5 \mu \mathrm{g}, 6 \mu \mathrm{g}, 7 \mu \mathrm{g}, 8 \mu \mathrm{g}, 9 \mu \mathrm{g}$ and $10 \mu \mathrm{g}$ drug per ml solution) were made with $0.1 \mathrm{~N} \mathrm{HCl}$ To a series of $10 \mathrm{ml}$ volumetric flasks aliquots standard solutions were taken and the volume was made up using a $0.1 \mathrm{~N} \mathrm{HCl}$. The absorbance of these solutions was measured at respective wave length of maximum absorbance (239 $\mathrm{nm}$ ) in UV Visible spectrophotometer. Standard calibration curve was obtained by plotting Absorbance values against respective concentration.

\section{Solubility study of drug}

Solubility of nifedipine was determined in various solvents. Excess Nifedipine (i. e Saturated solubility) was dispersed and stirred in different solvents for $48 \mathrm{~h}$ at room temperature. Filter the solutions, weighed accurate quantities of the filtered supernatants, dilute the filtrate for further analysis by using spectrophotometrically at 
$239 \mathrm{~nm}$. from the obtained data the solubility of nifedipine was calculated in the respective liquid vehicle [16].

\section{Compatibility studies}

Drug and excipients compatibility studies by FTIR spectrophotometer

The infrared spectra of pure drug and mixture of polymers and excipients were studied by FT IR spectroscopy using the KBR. The $\mathrm{KBr}$ discs were prepared by compressing the powders at pressure of 5 tons for $5 \mathrm{~min}$. in a hydraulic press. Scans were obtained at a resolution of 4 $\mathrm{cm}^{-1}$; from 4000 to $600 \mathrm{~cm}-1$ here spectral changes in the mixture are the basis for the determination of compatibility. The obtained spectrums of different formulation combinations were shown below. The spectral analysis of the pure drug and excipients mixture were done [17].

\section{Method of preparation of nifedipine lipotome}

\section{Hydration of thin lipid film (Bangham method)}

Nifedepine loaded Lipotomes was prepared using a thin film hydration technique. The drug ( $30 \mathrm{mg}$ ) Tween 80 ), Cetyl Alcohol were weighed and dissolved in $10 \mathrm{ml}$ of $(2: 1 \mathrm{v} / \mathrm{v})$ mixture of chloroform: methanol in a $250 \mathrm{ml}$ round-bottom flask [11]. The organic solvent was slowly evaporated using a rotary evaporator revolving at $150 \mathrm{rpm}$ for $15 \mathrm{~min}$ at $75^{\circ} \mathrm{C}$ under reduced pressure. After the formation of a thin dry film, thin film expose in phosphate buffer PH 7.4 for hydration. Appeared suspension will be agitated for $30 \mathrm{~min}$ and then sonicated for $1 \mathrm{Hr}$ for size reduction.

Initially nine bathes of Different concentration of CA: Tween $80 \mathrm{w} / \mathrm{w}$ (F1-F9) was prepared. Based in Particle size and entrapment efficiency F4, F5, F6 showed the least particle size and maximum entrapment efficiency as shown in table 5 . For optimization of bath $3^{2}$ factorial design was applied.

\section{Statistical design study}

To study the influence of the different variables used for preparation, as a characteristic of formulated lipotomes Central composite experimental design Design-Expert software was used. (version 12) In this design and within 9 runs, two factors were evaluated. The independent variables were lipid: surfactant $\mathrm{w} / \mathrm{w}$ ratio (X1) and X2= Rotations per minute (RPM) (X2). The the dependent variables are particle size (Y1: PS), Entrapment efficiency (Y2: EE) and Zeta potential (Y3: ZP) were selected.

Table 1: Experimental designing by $3^{2}$ factorial

\begin{tabular}{lllll}
\hline Formulation variables & \multicolumn{2}{c}{ Levels coded } & Dependent variable \\
\cline { 2 - 4 } & $\mathbf{- 1}$ & $\mathbf{0}$ & $\mathbf{+ 1}$ & \\
\hline $\mathrm{X} 1=$ lipid: surfactant w/w ratio & $1: 4$ & $1: 5$ & $1: 6$ & Y1=Particle size (nm) Y2=Entrapment Efficiency (\%) Y3=Zeta \\
$\mathrm{X} 2=$ Rotations per minute(RPM) & 130 & 150 & 170 & potential \\
\hline
\end{tabular}

Table 2: A $3^{2}$ Full factorial experimental design layout

\begin{tabular}{|c|c|c|}
\hline \multirow[t]{2}{*}{ Formulation code } & \multicolumn{2}{|c|}{ Coded factor levels } \\
\hline & $\mathrm{X1}$ & $\mathrm{X} 2$ \\
\hline F1 & -1 & -1 \\
\hline $\mathrm{F} 2$ & 0 & -1 \\
\hline F3 & +1 & -1 \\
\hline $\mathrm{F} 4$ & -1 & 0 \\
\hline F5 & 0 & 0 \\
\hline F6 & +1 & 0 \\
\hline F7 & -1 & +1 \\
\hline F8 & 0 & +1 \\
\hline F9 & +1 & +1 \\
\hline
\end{tabular}

\section{Characterization of lipotomes}

\section{Particle size analysis}

Determination of average particle size of lipotomes was very important characteristic. It was determined by using MALVERN INSTRUMENTS, DRSSK LABS PVT. LTD.

\section{Entrapment efficiency}

The entrapment efficiency of lipotomes will be determined by ultracentrifugation at $30,000-40,000 \mathrm{rpm}$ and $4{ }^{\circ} \mathrm{C}$ for 1 hour using ultracentrifuge. Following centrifugation, the supernatant and vesicles will be separated. The supernatant will be removed and drug quantity will be analyzed by analytical method. The percentage of drug encapsulated was determined after lysis of the prepared lipotomes with absolute alcohol and sonication for $10 \mathrm{~min}$. The concentration of Nifedipine in absolute alcohol was determined spectrophotometrically at $239 \mathrm{~nm}$ using a UV-visible spectrophotometer. The encapsulation efficiency expressed as entrapment percentage was calculated through the following relationship [18-21].

$$
\text { Entrapment efficiency } \%=\frac{\text { Total drug }- \text { free drug }}{\text { Total drug }} \text { X100 }
$$

\section{Zeta potential}

Zeta potential of the diluted samples was measured for each formula to evaluate its physical stability Measurements were done in triplicates for three independent samples from each formula and then the average values SD were calculated.

\section{Lyophilization of lipotomes}

Different cryoprotectants were mixed with optimized lipotomal batch. The selected cryoprotectants were aerosol and mannitol used in four different concentrations $(2 \%, 4 \%, 6 \%, 8 \%)$ The lyophilized formulae in presence of surfactants took the abbreviation from NL1 to NL8 where NL1-NL4 formulae were containing mannitol and NL4-NL8 formulae were containing Aerosil,

The saccharides or cryoprotectants were dissolved in PBS buffer at different concentrations of 2, 4, 6, and 8\% of dry lipids. Lipotomal suspensions were diluted in an equal volume of each saccharide buffered solution in $50 \mathrm{ml}$ tubes, at $10 \%$ of fill volume. As control, lipotomal suspension was diluted in equal volume of PBS buffer. A very low freezing temperature seems to avoid damage of nanoparticles. Considering these assumptions, all the liposomal suspensions were stored for $6 \mathrm{~h}$ in a deep freezer and then freezedried for $24 \mathrm{~h}$ in chamber with pressure $6 \mathrm{~Pa}^{3}[22,23]$.

\section{Characterization of the lyophilized nifedipine lipotomes \\ Determination of moisture content and reconstitution time}

Moisture content of the lyophilized lipotomal formulations was analyzed using Karl Fischer titrator. The initial moisture content in $0.5 \mathrm{gm}$ of the investigated lyophilized formulations was determined and expressed as \%w/w. 
Reconstitution time; accurately weighed amounts of the lyophilized formulations were reconstituted using equal volume of distilled water as that being removed during the lyophilization process. The samples were reconstituted using vortex. The time (reconstitution time) taken by the lyophilized lipotomes to form an aqueous dispersion without any aggregates was measured. Each experiment was conducted in triplicates for each formula and the mean values SD were calculated [24].

\section{Particle size of lyophilized lipotomes}

PS of the lyophilized Nifedipine lipotomes were analyzed after reconstitution. The same analyzing method, as in case of lipotomal dispersions was used.

\section{Scanning electron microscopy}

Surface morphology of the Lyophilized lipotomal formulations was investigated using SEM (JXA-840; JEOL, Japan), after being coated with gold under vacuum [25].

\section{RESULTS AND DISCUSSION}

\section{Construction of standard calibration curve for nifedipine}

Calibration curves of Nifedipine in $0.1 \mathrm{~N}$ HCL is represented in fig. 1. The curves were linear at the concentration range of $1-10 \mu \mathrm{g} / \mathrm{ml}$ with regression values of 0.9985 . The high regression values indicate that the calibration curves follow Beer's law.

Table 3: Standard readings of nifedipine in UV

\begin{tabular}{ll}
\hline Concentration $(\boldsymbol{\mu g} / \mathbf{m l})$ & Absorbance at $\mathbf{2 3 9} \mathbf{~ n m}$ \\
\hline 0 & 0 \\
1 & 0.166 \\
2 & 0.336 \\
3 & 0.493 \\
4 & 0.643 \\
5 & 0.780 \\
6 & 0.9523 \\
7 & 1.114 \\
8 & 1.288 \\
9 & 1.399 \\
10 & 1.598 \\
\hline
\end{tabular}

\section{Solubility of nifedipine}

The saturated solubility of Nifedipine in water was found to be equal to $0.003 \mathrm{mg} / \mathrm{ml}$, this indicated that the drug is very slightly soluble in water and it shows good solubility in methanol and chloroform as $0.25 \mathrm{mg} / \mathrm{ml}$ and $1.6 \mathrm{mg} / \mathrm{ml}$ respectively. it indicates methanol and Chloroform is good choice of solvent in method of preparation of lipotomes.

Solubility data of drug nifedipine in various liquid vehicles is shown in table 4.

Table 4: Solubility of drug in different solvents

\begin{tabular}{ll}
\hline Solvent & Solubility $(\mathbf{m g} / \mathbf{m l})$ \\
\hline Methanol & $0.25 \pm 0.26$ \\
Chloroform & $1.6 \pm 0.90$ \\
Ethanol & $0.18 \pm 0.85$ \\
Water & $0.003 \pm 0.48$ \\
Tween 80 & $0.21 \pm 0.32$ \\
\hline
\end{tabular}

Values represent mean $\pm S D(n=3)$

\section{Compatibility studies}

Drug and excipients compatibility studies by FTIR spectrophotometer

Drug-excipients interaction was studied using Fourier transform infrared (FTIR) spectroscopy, and the results are presented in fig. 2, 3 , 4. Nifedipine demonstrates characteristic peaks in FTIR at 1225 cm-1 (due to its $\mathrm{CH}$ deformation) and $1682 \mathrm{~cm}-1$ (due to $\mathrm{C}-\mathrm{C}$ stretching) [26]. In this study both Drug Nifedipine and Mixture of Drug with Excipients (Cetyl alcohol) showed the characteristic peak about at same wavelength.

From this study and the graphs based on peaks and wave numbers that specific functional group, no additional peaks were obtained which indicates that there is no significant interaction between drug and excipients.

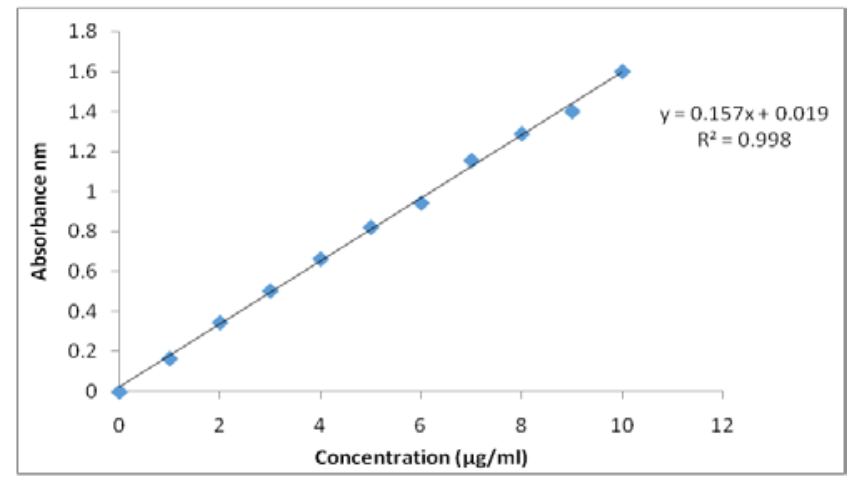

Fig. 1: Standard graph of nifedipine in $0.1 \mathrm{~N} \mathrm{HCl}$

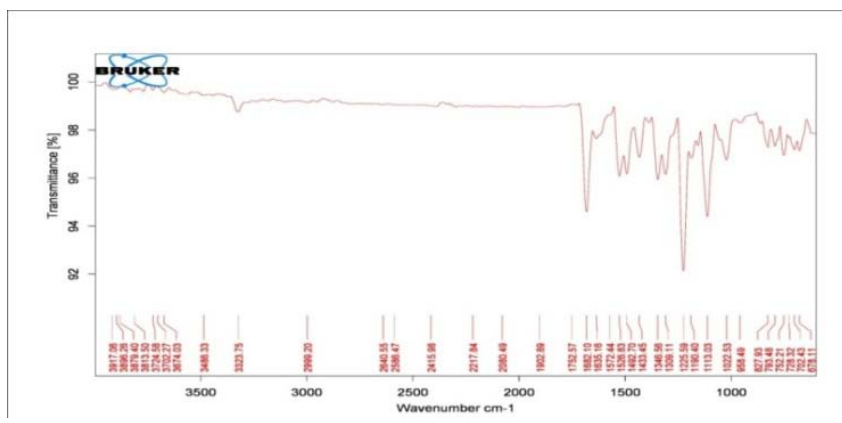

Fig. 2: FTIR of pure nifedipine 


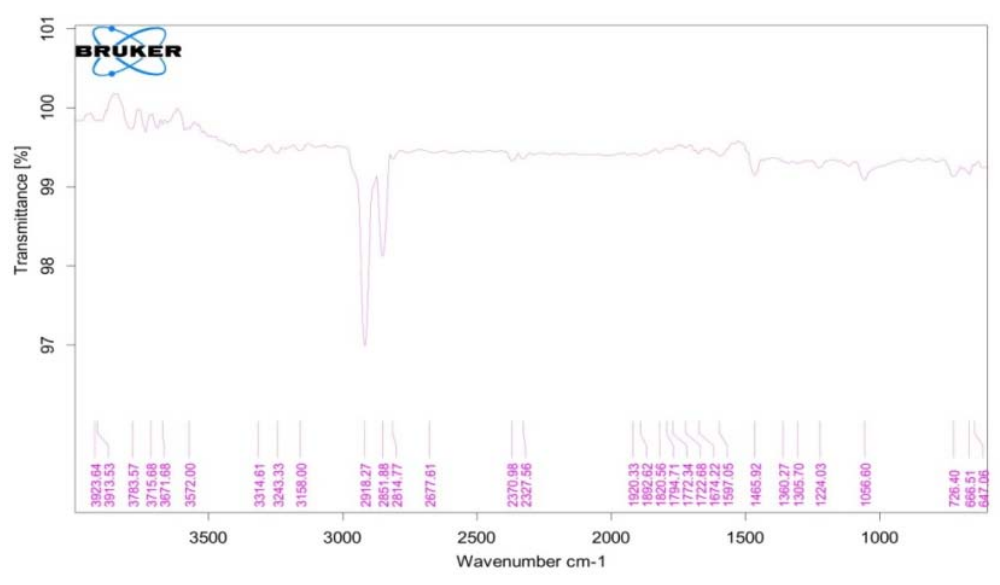

Fig. 3: FTIR of cetyl alcohol

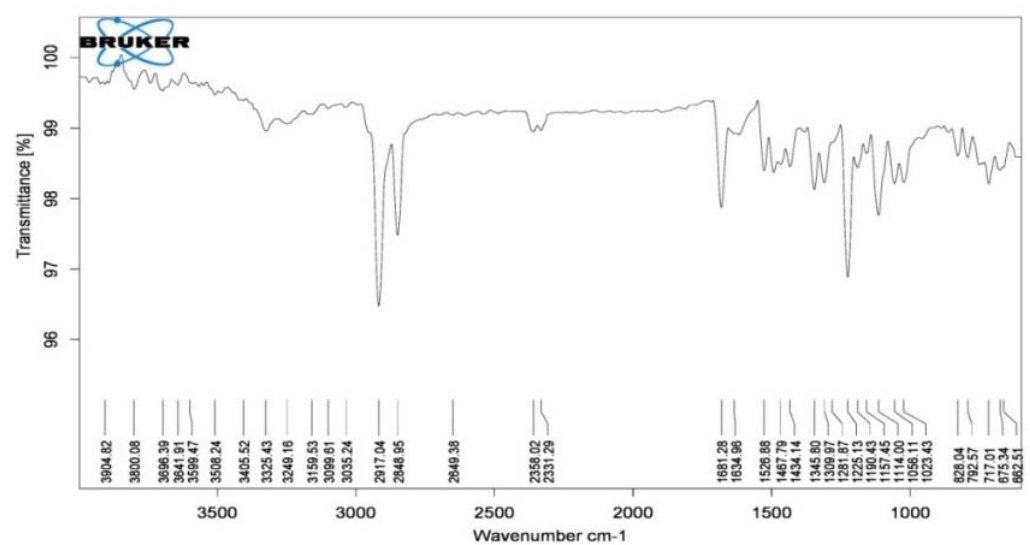

Fig. 4: FTIR of mixture of drug and excipient

\section{Characterization of prepared lipotomes}

Analysis of particle size, entrapment efficiency and zeta potential

Table 5: Particle size and entrapment efficiency of lipotomes prepared using film hydration method

\begin{tabular}{|c|c|c|c|c|c|}
\hline Formulations & CA: Tween $80 \mathrm{w} / \mathrm{w}$ & Drug (mg) & Chloroform: methanol (v/v) & Particle size (nm) & Entrapment efficiency (\%) \\
\hline F1 & $1: 1$ & 30 & $2: 1$ & $485.3 \pm 2.7$ & $79.1 \pm 3.2$ \\
\hline $\mathrm{F} 2$ & $1: 2$ & 30 & $2: 1$ & $567.2 \pm 3.9$ & $74.7 \pm 1.6$ \\
\hline F3 & $1: 3$ & 30 & $2: 1$ & $646.6 \pm 6.5$ & $69.6 \pm 2.7$ \\
\hline F4 & $1: 4$ & 30 & $2: 1$ & $218.1 \pm 7.1$ & $89.7 \pm 3.9$ \\
\hline F5 & $1: 5$ & 30 & $2: 1$ & $269.2 \pm 12.4$ & $96.3 \pm 1.1$ \\
\hline F6 & $1: 6$ & 30 & $2: 1$ & $293.2 \pm 10.4$ & $92.1 \pm 2.7$ \\
\hline F7 & $1: 7$ & 30 & $2: 1$ & $141.3 \pm 1.2$ & $88.8 \pm 2.1$ \\
\hline F8 & $1: 8$ & 30 & $2: 1$ & $159.3 \pm 11.2$ & $87.6 \pm 1.1$ \\
\hline F9 & $1: 9$ & 30 & $2: 1$ & $194.3 \pm 0.9$ & $82.8 \pm 4.2$ \\
\hline
\end{tabular}

Values represent mean $\pm S D(n=3)$

\section{Particle size}

By using different ratio of Tween 80 and cetyl alcohol nifedipine lipotomes was prepared and particle size of lipotomes varies from $308.1 \mathrm{~nm}$ to $404.3 \mathrm{~nm}$

Fig. 5A presents the effect of different factors on the mean PS. These investigated factors were $\mathrm{X} 1=$ lipid: surfactant $\mathrm{w} / \mathrm{w}$ ratio and $\mathrm{X} 2=$ Rotations per minute (RPM) from the presented figure, it is evident that both factors showed significant effects on the mean PS (pvalues $<0.001$ ). It was manifest that increasing the Tween 80 in case of factor (X1) and RPM in case of factor (X2) led to a significant decrease in the mean PS produced lipotomes with smaller particle size [19].

\section{Entrapment efficiency}

EE of all Nifedipine loaded lipotomes prepared formulations were within the range of $79.1 \%$ to $96.3 \%$, as shown in table 6 and fig. 5B. $\mathrm{X} 1=$ lipid: surfactant $\mathrm{w} / \mathrm{w}$ ratio and $\mathrm{X} 2=$ Rotations per minute (RPM) showed the significant effect on entrapment efficiency. Increase in lipid: surfactant $\mathrm{w} / \mathrm{w}$ ratio and RPM decrease in entrapment efficiency. Formulation (F4) which has 1:4 lipid: surfactant ratio and 150 RPM showed the maximum entrapment efficiency [27]. 


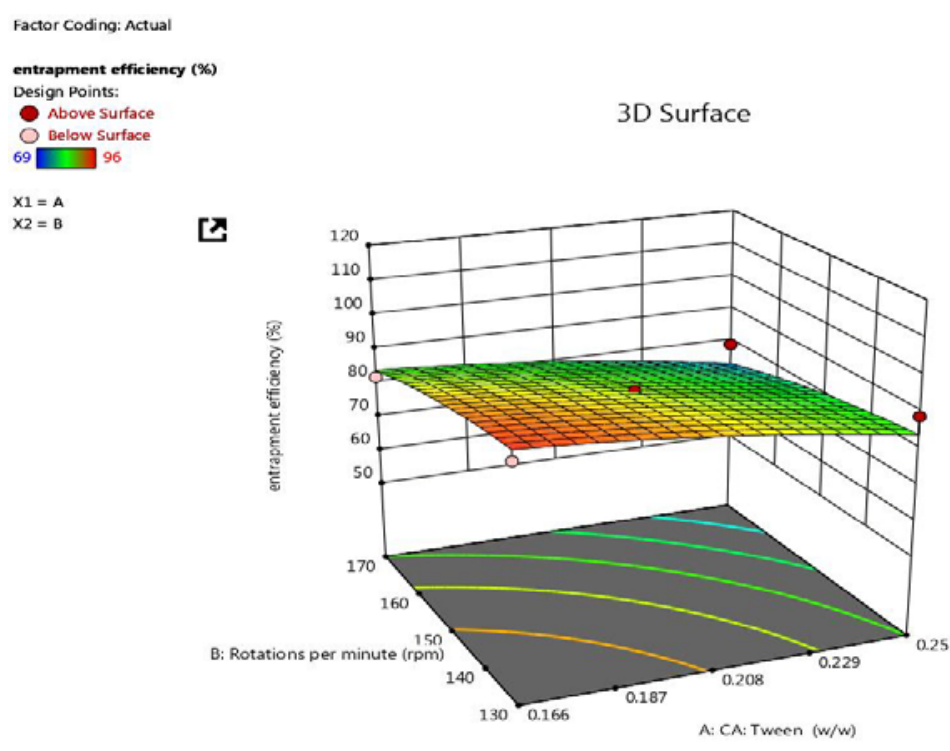

Fig. 5A: Response surface plots for the effects of lipid: surfactant $w / w$ ratio (X1) and rotations per minute (RPM) (X2) on the mean particle size of liposomal formulations

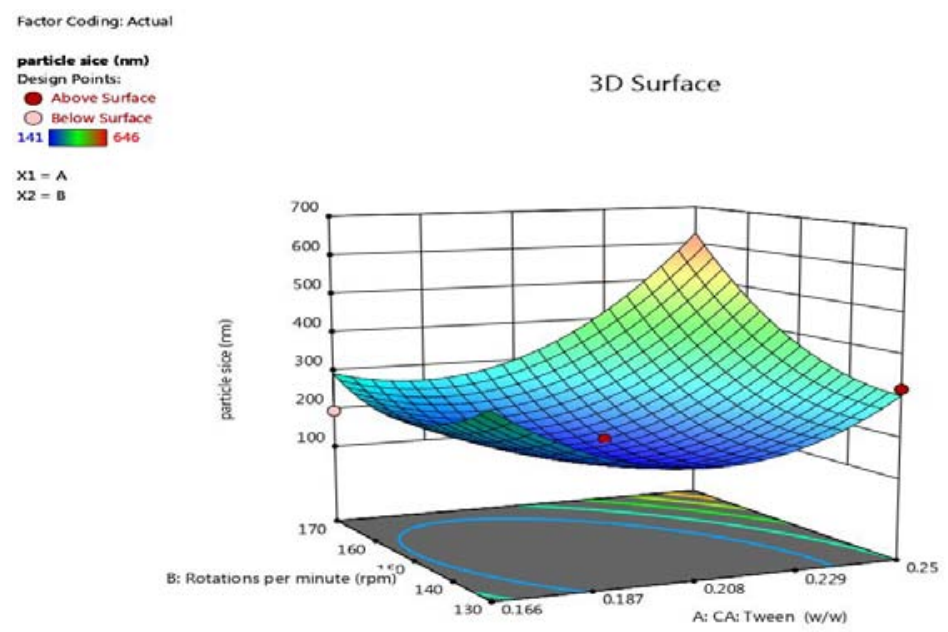

Fig. 5B: Response surface plots for the effects of lipid: surfactant $w / w$ ratio (X1) and rotations per minute (RPM) (X2) on entrapment efficiency of lipotomal formulations

\section{Zeta potential}

$\mathrm{ZP}$ values of the prepared formulations between-20.1and-26.7 $\mathrm{mV}$, as shown in table 6 the higher the zeta potential higher the repulsive force between particle which prevent aggregation of the nanovesicles. The zeta potential is a good indicator for the stability of the nanoparticles.
Nanoparticles carrying high electric charge will protect the nanoparticles in from aggregation due to the high repellent forces between the particles. It was previously mentioned that high absolute zeta potential values provide excellent stability for the nanoparticles [28]. From the zeta potential results, it is observed that obtained values will Shows a good degree of stability for all the prepared lipotomal formulations.

Table 6: Experimental runs, independent variables and measured responses of the $3^{2}$ full factorial experimental designs

\begin{tabular}{|c|c|c|c|c|c|}
\hline Formulae & $\begin{array}{l}\text { X1= lipid: surfactant } \\
w / w \text { ratio }\end{array}$ & $\begin{array}{l}\text { X2= Rotations per } \\
\text { minute (RPM) }\end{array}$ & $\begin{array}{l}\text { Y1 = Particle size } \\
\text { (nm) }\end{array}$ & $\begin{array}{l}\text { Y2= Entrapment } \\
\text { efficiency (\%) }\end{array}$ & $\begin{array}{l}\text { Y3 = Zeta } \\
\text { potential }(\mathrm{mV})\end{array}$ \\
\hline F1 & $1: 4$ & 130 & $385.3 \pm 2.69$ & $92.48 \pm 3.19$ & $-24.4 \pm 1.1$ \\
\hline F2 & $1: 5$ & 130 & $367.2 \pm 4.14$ & $94.2 \pm 5.17$ & $-22.1 \pm 1.0$ \\
\hline F3 & $1: 6$ & 130 & $346.6 \pm 3.81$ & $89.4 \pm 4.09$ & $-23.0 \pm 0.5$ \\
\hline F4 & $1: 4$ & 150 & $308.1 \pm 2.79$ & $96.7 \pm 5.31$ & $-20.1 \pm 0.2$ \\
\hline F5 & $1: 5$ & 150 & $389.2 \pm 4.29$ & $95.3 \pm 3.31$ & $-24.2 \pm 0.6$ \\
\hline F6 & $1: 6$ & 150 & $393.2 \pm 4.71$ & $90.1 \pm 5.44$ & $-26.7 \pm 0.8$ \\
\hline F7 & $1: 4$ & 170 & $341.3 \pm 2.16$ & $84.7 \pm 3.39$ & $-25.4 \pm 0.6$ \\
\hline F8 & $1: 5$ & 170 & $359.3 \pm 3.41$ & $92.6 \pm 4.61$ & $-26.1 \pm 1.0$ \\
\hline F9 & $1: 6$ & 170 & $404.3 \pm 5.52$ & $91.8 \pm 4.21$ & $-26.2 \pm 0.6$ \\
\hline
\end{tabular}

Values represent mean $\pm S D(n=3)$ 


\section{Optimization of lipotomes}

Nifedipine loaded lipotomes were prepared by film hydration method. The study showed that particle size and entrapment efficiency of drug was significantly affected by lipid: surfactant ratio and stirring Rate (RPM). so it was demonstrate that optimal formulation (F4) having lipid to surfactant ratio (1:4),chloroform to methanol ratio(2:1) and stirring rate (150RPM) was chosen best formula showing least particle size $(308.1 \mathrm{~nm})$ and maximum entrapment efficiency(96.7\%).

\section{Lyophilization of lipotomes}

Optimized lipotomal formula (F4) was used for lyophilization, to improve the drug stability and drug retention in lipotomes lyophilization was carried out of optimized batch by using different cyroprotectant as aerosol and mannitol used in four different concentrations $(2 \%, 4 \%, 6 \%, 8 \%)$. lyophilized formula containing $8 \%$ mannitol $(\mathrm{w} / \mathrm{v})$ showed minimum moisture content, good reconstitution time, proved to be suitable for further studies as invite and in vivo study. after lyophilization no significant changes occur in lipotomes particle size.

\section{Characterization of the lyophilized nifedipine lipotomes}

\section{Determination of moisture content and reconstitution time}

Prepared lyophilized lipotomes shows low moisture content ranging from $1.49 \pm 0.11$ to $2.59 \pm 0.01(\mathrm{w} / \mathrm{w})$ lipotomal formulations containing mannitol showed lower initial moisture content when compared to lipotomal formulations containing the same concentration of arosil where, formula NL4 containing $8 \%(\mathrm{w} / \mathrm{v})$ mannitol possessed the lowest moisture content, $1.49 \% \mathrm{w} / \mathrm{w}$ This difference was accredited to the ability of mannitol to resist moisture uptake in comparison to arosil. Lyophilized samples pretreated with cryoprotectants like mannitol or arosil showed better re-dispersion upon reconstitution. Moisture content and reconstitution time determined for lyophilized lipotomal formulations is represented in table 7. From the table, it is evident that the lyophilized lipotomes containing mannitol as cyroprotectant show the less moisture uptake and good redespersibility.

\section{Particle size}

Cyroprotectant with different concentrations was used for lyophilization, it was observed that $8 \%$ mannitol preserve the partical size of lipotomes no significant changes in particle size after lyophilizationthe. Mean particle size of lyophilized nifedipine lipotomes was shown in table 7.

\section{Scanning electron microscopy}

SEM was utilized to examine the morphology of the optimized lyophilized lipotomal formulations (NL4). Showed that the air-dried NL4 formula were regularly spherical in shape with smooth surface as shown in fig. 6.

Table 7: Moisture content, reconstitution time and particle size of lyophilized lipotomes

\begin{tabular}{llll}
\hline Formula & Moisturecontent $(\% \mathbf{w} / \mathbf{w})$ & Reconstitution time (min) & Particle size (nm) \\
\hline NL1 & $2.19 \pm 0.15$ & $1.91 \pm 0.10$ & $1019.13 \pm 3.07$ \\
NL2 & $1.93 \pm 0.11$ & $1.62 \pm 0.09$ & $929.17 \pm 6.65$ \\
NL3 & $1.73 \pm 0.20$ & $0.92 \pm 0.12$ & $817.12 \pm 9.56$ \\
NL4 & $1.49 \pm 0.11$ & $0.63 \pm 0.05$ & $318.6 \pm 2.97$ \\
NL5 & $2.59 \pm 0.01$ & $2.80 \pm 0.14$ & $998.52 \pm 7.18$ \\
NL6 & $2.31 \pm 0.08$ & $2.49 \pm 0.17$ & $813.19 \pm 9.56$ \\
NL7 & $1.84 \pm 0.17$ & $1.84 \pm 0.10$ & $654.50 \pm 8.54$ \\
NL8 & $1.69 \pm 0.05$ & $1.39 \pm 0.08$ & $519.28 \pm 5.51$ \\
\hline
\end{tabular}

Values represent mean $\pm S D(n=3), N L$ : Nifedipine lipotomes

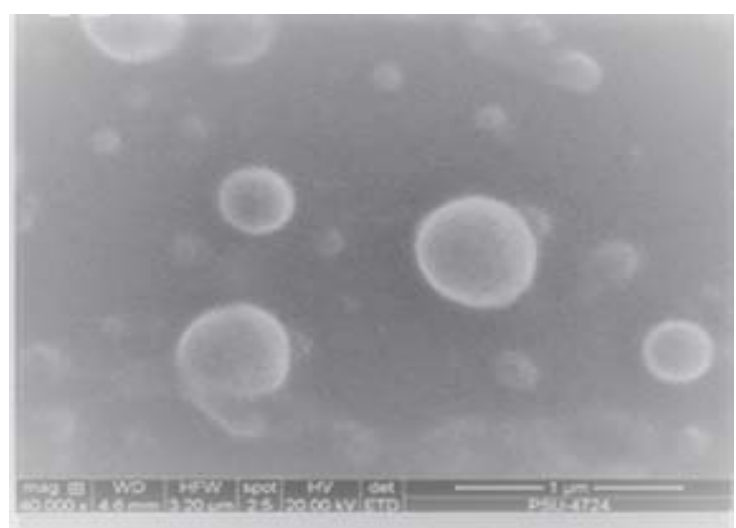

Fig. 6: SEM of lyophilized nifedipine lipotomes (NL4)

\section{Selection of the lyophilized lipotomal formula}

From the above results, it is observed that the lyophilized lipototoes (NL-4) formula pre-treated with 8\% mannitol (w/v) showed good result compared to other formulations. As lowest reconstitution time, PS and moisture content. Hence, formula NL-4 was selected for further investigations.

\section{CONCLUSION}

Lipotomes was prepared by using cetely alcohol and tween 80 which provide combine the lipophilic environment and solubilizing power respectively. That is, lipotomes offer dual action for enhancing drug's oral bioavailability. lipotomes is a stable and easily prepared platform for oral administration. The prepared lipotomes are mainly composed of lipophilic fatty alcohol and a hydrophilic surfactant, which create or provide microenvironment for the entrapment of a wide range of active ingredients. In this study, we designed nifedipine lipotomes by using film hydration method Hence, optimized lyophilized lipotomes was prepared at the chosen optimal factors composition, and its evaluation showed development of a successful formulation with very good compatibility, convenient particle size and high drug entrapment efficiency. This study concludes. However in further studies lyophilized lipotomes formulation to be used as better option of the conventional drug delivery system in the treatment of hypertension. further investigations need to be conducted in vitro and in vivo study.

\section{FUNDING}

Nil

\section{AUTHORS CONTRIBUTIONS}

All authors have contributed equally.

\section{CONFLICT OF INTERESTS}

The author has no conflict of interest to declare.

\section{REFERENCES}

1. Mantas A, Mihranyan A. Immediate-release nifedipine binary dry powder mixtures with nanocellulose featuring enhanced solubility and dissolution rate. Pharmaceutics 2019;11:37.

2. Hecq J, Deleers M, Fanara D, Vranckx H, Amighi K. Preparation and characterization of nanocrystals for solubility and 
dissolution rate enhancement of nifedipine. Int J Pharm 2005;299:167-77.

3. Beaubien AR, Pakuts AP. Influence of dose on first-pass kinetics of ${ }^{14} \mathrm{C}$-imipramine in the isolated perfused rat liver. Drug Metab Dispos 1979;7:34-9.

4. Dahlstrom BE, Paalzow LK. Pharmacokinetic interpretation of the enterohepatic recirculation and first-pass elimination of morphine in the rat. J Pharmacokinet Biopharm 1978;6:505-19.

5. De Boer AG, Breimer DD, Pronk, Gubbens Stibbe JM. Rectal bioavailability of lidocaine in rats: absence of significant firstpass elimination. J Pharm Sci 1980;69:804-7.

6. Moffat AC, Osselton MD, Widdop B. Clarke's analysis of drugs and poisons. $3^{\text {rd }}$ ed. NY: Pharmaceutical Press; 2005.

7. El-Mahrouk GM, El-Gazayerly ON, Aboelwafa AA, Taha MS. Chitosan lactate wafer as a platform for the buccal delivery of tizanidine $\mathrm{HCl}$ : in vitro and in vivo performance. Int J Pharm 2014;467:100-12.

8. Patel RB, Patel MR, Bhatt KK, Patel BG, Gaikwad RV. Evaluation of brain targeting efficiency of intranasal microemulsion containing olanzapine: pharmacodynamic and pharmacokinetic consideration. Drug Delivery 2014;20:1-9.

9. FDA. Defoaming agents used in coatings. In: Indirect food additives: paper and paperboard components. Maryland WA USA: US Food and Drug Administration; 2018.

10. FDA. Polysorbate 80. In: Food additives permitted for direct addition to food for human consumption. Maryland WA. USA: US Food and Drug Administration; 2018.

11. Elkasabgy NA, Elsayed I, Elshafeey AH. Design of lipotomes as a novel dual functioning nanocarrier for bioavailability enhancement of lacidipine: in vitro and in vivo characterization. Int J Pharm 2014;472:369-79.

12. Capco DG, Chen Y. Nanomaterial: Impacts on cell biology and medicine. Germany: Springer; 2014.

13. Chun HJ, Park $\mathrm{CH}$, Kwon IK, Khang G. Cutting edge enabling technologies for regenerative medicine. Singapore: Springer; 2018.

14. Andronescu E, Grumezescu AM. Nanostructures for oral medicine. Amsterdam, Netherlands: Elsevier Science; 2017.

15. Bangham AD, Standish MM, Watkins JC. Diffusion of univalent ions across the lamellae of swollen phospholipids. J Mol Biol 1965;13:238-52.

16. Javadzadeh Y, Musaalrezaei, Nokhodchi A. Liquisolid technique as a new approach to sustain propranolol hydrochloride release from tablet matrices. Int J Pharm 2008;362:102-8.
17. Jagdale S, Salil M, Barhate A. Design and evaluation of enteric press-coated tablet for pulsatile delivery of atenolol. Int J Pharm World Res 2010;1:11-5.

18. Aburahma M, Abdelbary G. Novel diphenyl dimethyl bicarboxylate provesicular powders with enhancedhepato curative activity: preparation, optimization, in vitro/in vivo evaluation. Int J Pharm 2012;422:139-50.

19. $\mathrm{Xu} \mathrm{H}, \mathrm{He} \mathrm{L}$, Nie S. Optimized preparation of vinpocetine proliposomes by a novel method and in vivo evaluation of its pharmacokinetics in New Zealand rabbits. J Controlled Release 2009;140:61-8.

20. Elhissi A, Hidayat K, David A. Air-jet and vibrating-mesh nebulization of niosomes generated using particulate-based proniosome technology. Int J Pharm 2013;444:193-9.

21. Soliman SM, Abdelmalak NS, El-Gazayerly ON, Abdelaziz N. Novel non-ionic surfactant proniosomesfor transdermal delivery of lacidipine: optimization using ${ }^{23}$ factorial design and in vivo evaluation inrabbits. Drug Delivery 2016;23:1608-22.

22. De Jaeghere F, Allemann E, Feijen J, Kissel T, Doelker E. Freezedrying and lyopreservation of diblock and triblock poly(lactic acid)-poly(ethylene oxide) (PLA-PEO) copolymer nanoparticles. Pharm Dev Technol 2000;5:473-83.

23. Moretton MA, Chiappetta DA, Sosnik A. Cryoprotectionlyophilization and physical stabilization of rifampicin-loaded flower-like polymeric micelles. J R Soc Interface 2012;9:487-502.

24. Abdelwahed W, Degobert G, Stainmesse S, Fessi H. Freezedrying of nanoparticles: formulation, process and storage considerations. Adv Drug Delivery Rev 2006;58:1688-713.

25. Aggarwal G, Chandel P, Harikumar S, Bansal S. Design and development of cefdinir niosomes for oraldelivery. J Pharm Bioallied Sci 2013;5:318.

26. Kunasekaran V, Krishnamoorthy K. Compatibility studies of rasagiline mesylate with selected excipients for an effective solid lipid nanoparticles formulation. Int J Pharm Pharm Sci 2015;7:73-80.

27. Annadurai G, Ling LY, Lee JF. Statistical optimization of medium components and growth conditions byresponse surface methodology to enhance phenol degradation by Pseudomonas putida. J Hazard Mater 2008;151:171-8.

28. Gawali SL, Barick BK, Barick KC, Hassan PA. Effect of sugar alcohol on colloidal stabilization of magnetic nanoparticles for hyperthermia and drug delivery applications. J Alloys Compd 2017;725:800-6. 